\title{
O LIVRO DIDÁTICO COMO INTERLOCUTOR NO ENSINO DA ESTATÍSTICA NO ENSINO MÉDIO
}

A. A. CORRÊA ${ }^{\mathbf{1}^{*}}$ e J. B. ROCHA FILHO ${ }^{2}$
$\begin{gathered}{ }^{1} \text { Universidade Regional Integrada do Alto Uruguai e das Missões - URI } \\ { }^{2} \text { Pontifícia Universidade Católica do Rio Grande do Sul - PUCRS } \\ \text { aleacorrea@yahoo.com.br }{ }^{*}\end{gathered}$
Artigo submetido em agosto/2013 e aceito em abril/2015
DOI: $10.15628 /$ holos.2015.1588

\section{RESUMO}

Os saberes docentes mobilizados pelos professores de Matemática do Ensino Médio em suas práticas de ensino da Estatística constituíram o alvo de uma pesquisa cujos resultados são apresentados neste artigo. Entendeu-se que os estudos acerca da formação docente ou da constituição da docência, na contemporaneidade, tendem a secundarizar o papel das práticas dos professores, negligenciando os saberes produzidos. Ao instaurar um campo analítico, a pesquisa pretendeu diagnosticar e compreender os saberes colocados em ação no ensino de conteúdos estatísticos. A partir das respostas dos questionários aplicados a professores do Ensino Médio, percebeu-se que os saberes da ação pedagógica, estão presentes nas práticas docentes, sendo que um dos interlocutores utilizados é o livro didático onde os saberes estatísticos são mobilizados pelos docentes do Ensino Médio.

PALAVRAS-CHAVE: Ensino, educação estatística, docência, Brasil.

\section{THE TEXTBOOK AS INTERMEDIATE IN TEACHING STATISTICS IN SECONDARY EDUCATION}

\begin{abstract}
The teaching knowledge mobilized by mathematics teachers of high school in their teaching of statistics were the target of a survey whose results are presented in this article. It was understood that the studies on teacher training or the constitution of teaching tend to into second the role of teacher practice, neglecting the knowledge produced. By establishing a field analytical research intended to diagnose and understand the
\end{abstract}

knowledge put into action the teaching content statistics. From the answers of the questionnaires given to teachers of high school, it was realized that the knowledge of pedagogical action, are present in teaching practices, and one of the speakers used is the textbook where knowledge statistics are mobilized for teaching in secondary .

KEYWORDS: Education, education statistics, teaching, Brazil. 


\section{INTRODUÇÃO}

O presente trabalho, ao examinar modos de desenvolvimento profissional de professores no Ensino Médio, toma como objeto de análise os saberes docentes mobilizados pelos professores de Matemática em suas práticas de ensino da Estatística. Seu objetivo é diagnosticar e compreender os saberes colocados em ação no ensino de conteúdos ligados à Estatística, ampliando o olhar sobre as várias perspectivas que constituem a formação docente, incluindo os saberes docentes como um campo significativo tanto para a constituição dos conhecimentos da área, quanto às possibilidades de desenvolvimento profissionais qualificados.

Os saberes estatísticos, conforme Batanero (2002), Gal (2002) e Lopes (2008), cada vez mais cedo passam a integrar os currículos escolares, sobretudo na análise de questões econômicas e sociais. Nessa direção, adquire força a necessidade de que o professor compreenda e utilize adequadamente conhecimentos estatísticos contextualizados. Assim, pensar o Ensino Médio desafia os professores a buscarem aportes teóricos para compreenderem as relações existentes entre as aprendizagens, os processos de educação e o papel do professor diante da formação de um cidadão ético e autônomo intelectualmente.

Diante dessas condições, examinam-se questões relativas ao desenvolvimento profissional docente e ao ensino da Estatística. A questão norteadora do estudo foi: Que saberes docentes estão presentes nas práticas pedagógicas dos professores de Matemática do Ensino Médio ao ensinarem Estatística? Para desenvolver esse processo, metodologicamente optou-se por uma abordagem qualitativa e de caráter compreensivo. O instrumento para a coleta de dados foi um questionário misto, sendo sujeitos da investigação oito professores do Ensino Médio que atuam nas redes públicas e privadas da cidade de Canela, no Rio Grande do Sul. Para o tratamento das informações foi considerada a Análise Textual Discursiva, inspirada em Moraes e Galiazzi (2007).

Para fins desse texto, serão examinados especificamente os saberes derivados da ação pedagógica. Como hipótese a ser desenvolvida, trabalha-se com a perspectiva de que os saberes que envolvem o uso do livro didático seria uma das principais ferramentas teóricas para ensinar Estatística no Ensino Médio, contribuindo para o desenvolvimento profissional dos professores e para a qualificação de sua ação pedagógica.

\section{REVISÃO BIBLIOGRÁFICA}

Ao mencionar conceitos estatísticos, não se pode deixar de comentar a influência que a Estatística possui sobre as decisões que afetam indireta e diretamente toda a sociedade. Nessa direção, o conhecimento estatístico torna-se ferramenta fundamental nos currículos e no ensino escolar. Lopes (2004) complementa, afirmando que

A pesquisa em educação estatística tem destacado a importância de se considerar o papel dessa ciências na tomada de decisões a que as pessoas estão sujeitas em seu cotidiano e que essa perspectiva deve ser assumida no currículo da escola (LOPES, 2004, p. 188). 
Tomando-se como ponto de partida a reflexão de Lopes (2008), percebe-se o quanto a Estatística está presente no cotidiano, tanto em meios midiáticos, quanto tecnológicos; porém, necessita-se ter conhecimento específico sobre conceitos estatísticos. Uma definição da Estatística indica que ela constitui-se como "uma ciência que se dedica ao desenvolvimento e ao uso de métodos para a coleta, resumo, organização, apresentação e análise de dados" (FARIAS; SOARES; CÉSAR, 2003, p. 18). Outras definições são mais específicas, como a utilizada por Batanero:

La estadística estudia el comportamiento de los fenómenos llamados de colectivo. Está caracterizada por una información acerca de un colectivo o universo, lo que constituye su objeto material; un modo propio de razonamiento, el método estadístico, lo que constituye su objeto formal y unas previsiones de cara al futuro, lo que implica um ambiente de incertidumbre, que constituyen su objeto o causa final (CABRIÁ apud BATANERO, 2001, p. 6).

Nessa segunda definição, percebe-se que há outros elementos que são levados em consideração como "os fenômenos chamados de coletivo" (ibidem, tradução nossa). Em outras palavras, refere-se à aleatoriedade, que influencia os métodos estatísticos, pois traz consigo incertezas, exigindo que se tenha um raciocínio reflexivo e coerente.

Complementando a ideia de coletividade, Lopes enfatiza que

Seria importante observar que o ensino da Estatística não poderia vincular-se a uma definição da Estatística restrita e limitada, isto é, a uma simples coleta, organização e representação de dados, pois este tipo de trabalho não viabilizaria a formação de um aluno com pensamentos e postura críticos (LOPES, 1998, p. 114).

Dessa forma, o ensino da Estatística poderia estar voltado para a formação de conceitos, bem como para a elaboração de procedimentos, métodos e modelos. Enfim, segundo a concepção de Lopes (1998), seria significativo que o pensamento estatístico crítico estivesse presente para o ensino e a aprendizagem, ou seja, que a Educação Estatística oportunizasse situações de aprendizagem nas quais o sujeito fosse o ator principal na construção de seus conhecimentos.

Acrescentando informações, segundo os PCN's (1997), pode-se enunciar que há habilidades específicas para o ensino da Estatística, como utilizar, estimar e expressar, por meio de instrumentos de medida, representações usuais ou não e, em etapa posterior, coletar, elaborar e interpretar dados, estando eles expressos em forma de gráficos, tabelas, esquemas, comunicando os resultados de suas estratégias. Além disso, os PCN's consideram que o uso da Estatística pode constituir-se como uma ferramenta que propicie ao aluno o desenvolvimento de uma postura crítica diante das informações, pois, exigindo-o habilidades como interpretar amostras, tanto tabulares como gráficas podendo fazer previsões e tomar baseados em dados estatísticos.

Também se percebem relações entre os objetivos do Relatório Pedagógico do ENEM (BRASIL, 2007) e as Orientações Curriculares do Ensino Médio (BRASIL, 2006). Ambos os documentos partem do entendimento de que o Ensino Médio deve preparar o sujeito para o trabalho, para assumir de forma consciente o seu papel de cidadão, com a ética, a autonomia 
intelectual e a assimilação dos processos produtivos sendo alicerces da sua formação escolar (BRASIL, 2006). E para que este processo ocorra, as Orientações Curriculares salientam que o "ensino da Matemática pode contribuir para que os alunos desenvolvam habilidades relacionadas à representação, compreensão, comunicação, investigação e, também, à contextualização sociocultural" (BRASIL, 2006, p. 69).

Quando se trata da Estatística, segundo as Orientações Curriculares do Ensino Médio apresenta-se

O estudo da estatística viabiliza a aprendizagem da formulação de perguntas que podem ser respondidas com uma coleta de dados, organização e representação. Durante o ensino médio, os alunos devem aprimorar as habilidades adquiridas no ensino fundamental no que se refere à coleta, à organização e à representação de dados. Recomenda-se um trabalho com ênfase na construção e na representação de tabelas e gráficos elaborados, analisando sua conveniência e utilizando tecnologias, quando possível. Problemas estatísticos realísticos usualmente começam com uma questão e culminam com uma apresentação de resultados que se apoiam em inferências tomadas em uma população amostral (BRASIL, 2006, p. 78).

Segundo essa documentação revisada, no processo de aprendizagem, especialmente no Ensino Médio, o aluno já deve ter noções básicas sobre como quantificar e interpretar resultados, pois estamos inseridos em uma sociedade que prioriza a quantificação das informações. A Educação Estatística vai ao encontro dessa perspectiva, pois a investigação estimula a compreensão de forma indutiva e formal dos principais conceitos e representações estatísticas. Isso pode envolver a discussão crítica, a argumentação racional e o uso da linguagem estatística adequada para a interpretação e validação de informações que são vinculadas ao nosso cotidiano.

\section{METODOLOGIA}

Para fins da realização da investigação aqui apresentada, os sujeitos da investigação foram oito professores de Matemática que realizam suas atividades docentes no Ensino Médio nas redes pública estadual e privada da cidade de Canela - Rio Grande do Sul. A escolha desses sujeitos deu a partir dos seguintes critérios: a) ser professor da rede pública estadual ou privada; b) ter formação em Licenciatura em Matemática (concluída ou em andamento); c) trabalhar com conteúdos estatísticos em suas práticas pedagógicas. A partir da operacionalização desses critérios, foi possível selecionar os sujeitos, assim como adequar sua escolha aos objetivos desta investigação.

Destaca-se ainda que foi utilizado um questionário com perguntas mistas (tanto abertas, quanto de múltipla escolha) sobre questões referentes às concepções e às práticas docentes relacionadas aos conhecimentos da Estatística. Considerou-se como questionário "uma série ordenada de perguntas que devem ser respondidas por escrito pelo informante" (SILVA e MENEZES, 2005, p.33).

Traçando um perfil dos sujeitos entrevistados é possível descrever que dos oito professores, dois eram do sexo masculino e seis do sexo feminino. Sendo que setenta e cinco por cento destes trabalham na rede pública estadual. $O$ tempo de docência dos professores fica entre 
oito meses e doze anos. Quanto ao grau de instrução dos mesmos setenta e cinco por cento possui graduação em Licenciatura em Matemática e o restante do grupo possui especialização em áreas afins da educação.

Em relação às experiências profissionais, percepções e concepções dos respondentes em relação ao ensino da Estatística, percebeu-se que todos atribuem a Estatística um lugar de relevância, justificando que conhecimentos estatísticos são importantes, pois estão presentes no cotidiano e nas avaliações de larga escala. Vale destacar também que, conforme os sujeitos dessa pesquisa, os saberes estatísticos estão ligados a outras disciplinas, sendo expressos em gráficos e tabelas, requerendo conceitos estatísticos para a sua interpretação. Quando questionados sobre - lugar que os conhecimentos estatísticos ocupam nos currículos de suas escolas diversas respostas emergem. Quatro professores relatam que a Estatística ocupa lugar apenas no terceiro ano do Ensino Médio. Um professor relata que no plano de estudos de sua instituição a

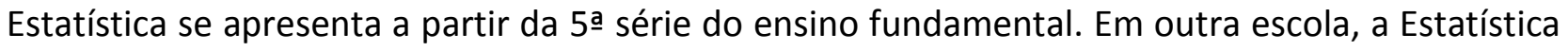
está presente no segundo ano do ensino médio. Dois professores ainda relatam que, em suas escolas, a Estatística não está presente na grade curricular.

Dos oito professores respondentes, três deles relatam que desde sua formação acadêmica até o presente momento não modificaram suas ações metodológicas em relação ao ensino da Estatística. Outros três não desenvolveram a questão e o restante dos professores relata que modificaram suas ações metodológicas buscando aproximar os conteúdos estatísticos ao contexto dos alunos. Assim, somente estes professores expõem que encontram dificuldades no ensino da Estatística, enfatizando que esta dificuldade está relacionada à compreensão das informações gráficas e dos conceitos estatísticos.

Quando perguntados sobre sua trajetória acadêmica e questões relacionadas à Estatística, seis professores relataram que estudaram Estatística no terceiro ano do Ensino Médio, um estudou no segundo ano da mesma etapa e um docente relata que não estudou Estatística na educação básica. Seguindo no mesmo viés, relacionando a Estatística e a formação dos docentes na educação básica, quando questionados como foram trabalhados os conteúdos estatísticos neste período os docentes evidenciam em suas respostas que situações problemas do cotidiano e retiradas de livros e jornais eram abordadas nas aulas, bem como o uso do livro didático, a análise de tabelas e gráficos presentes nos mesmos. Também há dois dos respondentes que relatam que os conceitos estatísticos foram apresentados de maneira "teórica", juntamente com a resolução de algoritmos e análise de gráficos. No que tange ao ensino superior, este quadro não se altera significativamente. Relatam que a Estatística foi ensinada por meio de conceitos teóricos, análise de dados coletados em pesquisas de campo, de situações-problema, de pesquisas estatísticas divulgadas pelo Instituto Brasileiro de Geografia e Estatística e de resolução de algoritmos.

\section{RESULTADOS E DISCUSSÕES}

Os saberes da ação pedagógica, segundo Pimenta (1999), provêm de diferentes áreas, nas quais o conhecimento, as experiências, os conteúdos específicos pedagógicos e didáticos tornamse importantes ferramentas presentes nas atividades cotidianas dos professores. A partir desse conjunto complexo de condições é que se constitui esse saber. A autora ressalta que as áreas precisam estar coesas e interligadas, uma vez que a principal função da utilização dos saberes é a 
constituição de uma aprendizagem baseada em práticas sociais - pressuposto importante para que os processos de aprendizagem se consolidem.

Seguindo esta perspectiva, percebe-se que os saberes pedagógicos estão em constante movimento, em constante mudança e em constante confrontação (PIMENTA, 1999). Isso desafia os docentes em seu ambiente de trabalho a pesquisar, a dialogar, a pensar em ações e atitudes que contribuam para o objetivo escolar; dessa forma, apresentam-se como saberes que estão na linha de frente com a qual os docentes interagem constantemente, e é indissociável da sua formação e prática profissional (PIMENTA, 1999).

Pimenta ainda enfatiza que, com o contato entre os saberes educacionais e os vinculados à pedagogia, é possível que docentes encontrem ferramentas e fomentem outras discussões para suas práticas. Vale ressaltar que ambas as áreas contribuem, com seus requisitos de experiência e conhecimento, para a construção de um profissional crítico e reflexivo.

Sobre esse segundo saber, Gauthier et al (2006, p. 33) apresenta outra visão, enfatizando que "o saber da ação pedagógica é o saber experiencial dos professores a partir do momento em que se torna prático e que é testado através das pesquisas realizadas em sala de aula". Dessa forma, o pesquisador coloca o saber da ação pedagógica como equivalente ao saber experiencial, porém cabe ressaltar que entre ambos os saberes, mesmo que poucas existem distinções (ibidem). O saber experiencial, conforme Gauthier et al (2006) leva o professor a acreditar e a elaborar quase um ritual de procedimentos para que a aprendizagem dos alunos seja efetiva. Porém, isso pode não ser a real explicação para a aprendizagem, assim "o que limita o saber experiencial é exatamente o fato de que é feito de pressupostos e de argumentos que não são verificados por meio de métodos científicos" (ibidem).

Ainda, o autor evidencia que o professor produz saberes experienciais, utilizando-se de percepções, concepções, técnicas, bom senso e outras qualidades que o ofício, ao longo da carreira, vai lhe ensinando. A partir dessa concepção, o saber apresenta-se de modo individualista, não havendo a propagação desses saberes no conjunto dos profissionais. Por sua vez, também não há sistematização, o que poderia auxiliar outros docentes que buscam por orientações disciplinares, curriculares ou pedagógicas.

O fator que distingue esses saberes, segundo Gauthier et al (2006), está relacionado à legitimação dessas experiências. Melhor explicando, enquanto os saberes docentes estiverem condicionados somente à sala de aula, não sendo pesquisados e validados pela comunidade científica, não podem ser considerados como saberes da ação pedagógica e integrando-se à identidade profissional do docente. E ressalta que

Os saberes da ação pedagógica legitimados pelas pesquisas são atualmente o tipo de saber menos desenvolvido no reservatório de saberes do professor, e também, paradoxalmente, o mais necessário à profissionalização do ensino (GAUTHIER et al, 2006, p. 34).

Esses saberes são os articuladores entre as práticas educativas e o papel que a instituição escolar possui. Dessa forma, o docente se vale de um conjunto didático oferecido ou não pelas instituições de formação de professores, para atingir seus objetivos tanto pessoais como profissionais. Buscam nos materiais - midiáticos, didáticos, entre outros - informações que o 
auxiliem no processo de aprendizagem e que estejam condizentes ao contexto em que está inserido.

\subsection{O livro didático: ferramenta para o ensino da estatística}

O livro didático é um dos mais antigos instrumentos de propagação do conhecimento escolar, pois, independentemente da época ou da cultura, em suas folhas ficavam registrados as verdades, anseios e descobertas de um determinado tempo e geração (BITTENCOURT, 2008). A primeira formulação indicativa deste material foi produzida por Comenius, no século XVI. O livro panmetódico, proposto pelo pensador clássico, apresentava-se como uma estratégia para que todos aprendessem os conteúdos desde uma mesma sequência, do mais simples ao mais complexo (NARODOWSKI, 2006). Assim, tal produto apresentava-se como um meio de registro para as produções culturais já consolidadas, convertendo-as em conhecimentos escolares. Por meio desses registros, a humanidade se apropriou dos diferentes fatos e saberes, conhecimentos científicos que, impressos, ganharam significados e representações diferentes.

Bittencourt (2008) apresenta o livro didático por meio de quatro perspectivas. A primeira, como mercadoria, na qual o mercado incentiva a fabricação e comercialização, atendendo as suas demandas por meio de técnicas cada vez mais elaboradas, ou seja, torna-se um produto destinado ao mundo mercadológico. A segunda perspectiva elucida que o livro didático pode ser "um depositário dos diversos conteúdos educacionais, suporte privilegiado para recuperar os conhecimentos e técnicas consideradas fundamentais por uma sociedade em determinada época" (ibidem, p. 14). Na terceira perspectiva, a autora refere-se ao livro didático como uma ferramenta pedagógica, e para tanto faz uso das palavras de Choppin (2004) para aprofundar essa perspectiva. Segundo este autor, o livro didático está "inscrito em uma longa tradição, inseparável tanto na sua elaboração como na sua utilização das estruturas, dos métodos e das condições do ensino de seu tempo" (CHOPPIN apud BITTENCOURT, 2008, p. 14). E, por último, a autora destaca que o livro é uma fonte condutora de valores e de ideias de uma cultura (BITTENCOURT, 2008).

Sobre o livro didático de Matemática, especificando essa argumentação, Dante (1996) aponta pontos positivos para a sua utilização e para a obtenção de resultados efetivos no ensino e na aprendizagem. Para o aluno, o livro didático apresenta definições, propriedades, tabelas, problemas, atividades e exercícios que podem auxiliar o aluno na aprendizagem; sendo os conteúdos sempre sequenciados e dependentes entre si. Em geral, o livro didático apresenta os conteúdos nesta ordem e por meio da resolução de problemas e atividades do livro didático, o aluno poderá desenvolver conceitos e habilidades essenciais para a aprendizagem (DANTE, 1996). Percebe-se que, para o autor, o aluno é capaz de aprender utilizando os livros didáticos que apresentam sequencialmente os conteúdos de forma completa (definições, propriedades, entre outras), desenvolvendo, assim, as habilidades e competências necessárias para sua aprendizagem em Matemática. Deste lugar, Dante afirma que o livro didático deve ser considerado pelo professor como "um meio e não o fim em si mesmo" (p. 89), pois este é responsável. $\mathrm{E}$, caso seja necessário, é preciso fazer uma releitura do conhecimento matemático presente no livro.

Para o professor, o livro didático constitui-se como uma ferramenta indispensável, sobretudo se este não atender às condições de uma formação adequada e consistente. Outra 
função do livro seria auxiliar o professor com atividades desafiadoras, textos explicativos e históricos, complementando o livro didático, que em muitos casos é o único recurso que a escola tem a oferecer ao professor e aluno (DANTE, 1996). Neste ponto, que relaciona professor e livro didático, nota-se que o livro é sugerido como um instrumento indispensável ao professor, nem sempre privilegiando as potencialidades e o conhecimento dos docentes.

Porém, cabe ressaltar que o autor também afirma, em seu texto intitulado Livro didático de Matemática: uso e abuso?, que "o livro didático, embora não deva ser o único, é um dos instrumentos essenciais na aprendizagem em sala de aula" (ibidem, p.88). Assim sendo, é necessário que o docente faça uso de maneira equilibrada e racional do livro, que pode ser iniciada com a escolha dos livros que são proporcionados pelo Programa - Nacional do Livro Didático - PNLD - criado em 1929 com outra denominação. Esse programa primeiramente está voltado para a distribuição de livros didáticos para estudantes da rede pública das diferentes etapas da educação básica (sobretudo ensino fundamental e médio). Conjuntamente ao PNLD, desde 2007 com a criação do Fundo de Manutenção e Desenvolvimento da Educação Básica e de Valorização dos Profissionais da Educação (FUNDEB) a educação infantil e o Ensino Médio também passaram a receber tais materiais didáticos, gradativamente em todas as áreas do conhecimento.

No Guia de Livros Didáticos, PNLD 2008 - Matemática, nota-se outra visão sobre o assunto, o qual enfatiza que o livro didático tem como funções

[...] oferecer informações e explicações sobre o conhecimento matemático que interfere e sofre interferências das práticas sociais do mundo contemporâneo e do passado. Também deve conter uma proposta pedagógica que leve em conta o conhecimento prévio e o nível de escolaridade do aluno e que ofereça atividades que o incentivem a participar ativamente de sua aprendizagem e a interagir com seus colegas. Além disso, o livro precisa assumir a função de texto de referência tanto para o aluno, quanto para o docente (BRASIL, 2007, p. 9).

Neste mesmo Guia (BRASIL, 2007), ao citarem os pesquisadores Gérard e Roegiers, outras funções específicas do livro didático para o aluno e para o docente são enunciadas. Para o aluno, as principais funções são:

- favorecer a aquisição de conhecimentos socialmente relevantes;

- propiciar o desenvolvimento de competências cognitivas, que contribuam para aumentar a autonomia;

- consolidar, ampliar, aprofundar e integrar os conhecimentos adquiridos;

- auxiliar na autoavaliação da aprendizagem;

- contribuir para a formação social e cultural e desenvolver a capacidade de convivência e de exercício da cidadania (BRASIL ${ }^{1}, 2007$, p.11 - 12).

Para os docentes, as funções seriam de outro nível:

- auxiliar no planejamento e na gestão das aulas, seja pela explanação de conteúdos curriculares, seja pelas atividades, exercícios e trabalhos propostos;

\footnotetext{
${ }^{1}$ GÉRARD e ROEGIERS, 1998 apud Brasil 2007, p. 11-12.
} 
- favorecer a aquisição dos conhecimentos, assumindo o papel de texto de referência;

- favorecer a formação didático-pedagógica;

- auxiliar na avaliação da aprendizagem do aluno (BRASIL ${ }^{2}, 2007$, p.12).

Partindo desse entendimento, o livro didático é visto como um interlocutor entre docente, aluno e conhecimento. Entretanto, entende-se que não deva ser considerado como a única ferramenta para esse diálogo, pois o docente deve ter e estabelecer limites entre a sua autonomia pedagógica e o livro didático. Pode, dentro do possível, adaptar, complementar, eliminar informações que acredita serem relevantes para seus alunos, e assim aproximar os conteúdos didáticos, tornando-os compreensíveis e parte integrante do seu contexto escolar.

Por meio desses apontamentos, percebe-se o porquê das discussões que cercam o assunto, as divergências e convergências na escolha e utilização deste objeto. O fato é que, conforme se viu acima, antes mesmo da invenção da imprensa, constata-se que o livro didático integra a cultura e as transformações que nela imperam. Por meio de suas imagens, escritos, textos e contextos, o conhecimento é disseminado, constituindo-se como um mediador entre os sujeitos aprendentes e a sociedade do seu tempo. O seu design e função de aprendizagem fazem com que o sujeito volte suas atenções, habilidades e competências diretamente a ele, o que propicia o ensino de qualquer assunto em qualquer sociedade. Assim, o docente em relação ao livro didático pode ser considerado o mediador dos conteúdos, e o aluno o receptor que assimila, transforma e ressignifica as informações, dependendo de suas percepções e conhecimentos prévios (BITTENCOURT, 2008).

Cabe reiterar que, em muitos casos, os livros didáticos são considerados bíblias do currículo, não somente pelos professores, mas também pelas instituições escolares que fazem dele seu principal orientador para a elaboração da grade curricular, cujos objetivos, ordem de conteúdos, avaliações, entre outros requisitos, são retirados das páginas do livro (BITTENCOURT, 2008). Diante desse suposto exagero, o livro talvez deixe de cumprir o seu papel, que, segundo Choppin (2004), tem a atribuição de sistematizar os referenciais - ideológicos e culturais -, instrumentalizar e documentar os conteúdos escolares.

Choppin (2004) destaca que, historicamente, o livro didático tem funções que se associam a fatores de ordem social, econômica, cultural, temporal, política, dentre outros. A primeira função, denominada pelo autor como função referencial, trata o livro didático como uma cópia do programa curricular a ser seguido, e argumenta que "em todo o caso, ele constitui o suporte privilegiado dos conteúdos educativos, o depositário dos conhecimentos, técnicas ou habilidades que um grupo social acredita que seja necessário transmitir às novas gerações" (ibidem, p. 553).

A segunda função do livro tem como objetivo auxiliar, facilitar, favorecer a implantação de métodos de aprendizagem por meio de exercícios ou atividades que visam à apropriação de competências e habilidades, para posteriormente serem ferramentas para as metodologias escolares, recebendo o nome de função instrumental (ibidem, p. 553).

Choppin (2004) enaltece ainda a influência cultural e a ideologia que os livros apresentam de uma determinada sociedade, sendo possível, segundo a visão do autor, afirmar que o livro didático é:

\footnotetext{
${ }^{2}$ GÉRARD e ROEGIERS, 1998 apud Brasil 2007, p.12.
} 
Instrumento privilegiado de construção de identidade, geralmente ele é reconhecido, assim como a moeda e a bandeira, como um símbolo da soberania nacional e, nesse sentido, assume um importante papel político. Essa função, que tende a aculturar - e, em certos casos, a doutrinar - as jovens gerações, pode se exercer de maneira explícita, até mesmo sistemática e ostensiva, ou, ainda, de maneira dissimulada, sub-reptícia, implícita, mas não menos eficaz (CHOPPIN, 2004, p. 553).

E ainda, Choppin (2004) aponta que o livro, nos contextos escolares, geralmente é visto como um formador de opinião, sendo possível que o aluno desenvolva a autonomia e a criticidade por meio da leitura livre. Assim, ele assume uma função documental no processo de aprendizagem.

Observa-se que, independente da função que o livro didático possua, ou mesmo que possa a vir a ter, ele abre espaço para as ciências dialogarem entre si, fazendo com que diferentes saberes sejam mobilizados (CHOPPIN, 2004). Primeiramente, dentro do esperado, o professor é que mobiliza esses saberes, pois necessita perceber as limitações que o instrumento apresenta diante do contexto escolar, adequando ênfases e atividades à realidade escolar, ou seja, tais saberes necessitam estar presentes para fazer do livro didático um representante do conhecimento científico no meio escolar.

Uma das premissas é de que o livro didático contempla não somente conceitos estatísticos, mas também outros campos do conhecimento. Essa posição atribuída a ele fez-se bastante recorrente nos materiais empíricos que compõem esta dissertação. Um primeiro campo de recorrências pode ser lido nos excertos a seguir.

Sujeito 6 - O livro didático é um material que temos sempre a mão e os exercícios, nos livros atuais, estão próximos à realidade do nosso aluno. Pelo menos meus colegas de escola sempre usam o livro didático como base para a Matemática do ensino médio.

Uma função do livro, segundo Chopin (2004) é auxiliar, facilitar, favorecer a implantação de métodos de aprendizagem por meio de exercícios ou atividades que visam à apropriação de competências e habilidades, para posteriormente serem ferramentas para as metodologias escolares, recebendo o nome de função instrumental.

Sujeito 4 - Com as situações-problemas que a maioria dos livros traz é possível relacionar o conteúdo com outras disciplinas, principalmente com geografia e biologia. Hoje em dia fala-se tanto em interdisciplinaridade, essas coisas, sabe! 0 livro, com seus gráficos e exemplos, ajuda $(\mathrm{m})$ a fazer isso. Para os conteúdos da estatística também é bom, porque os livros sempre trazem as questões de vestibular e agora do ENEM.

Neste outro apontamento, pode-se perceber que as informações e explicações do livro didático interferem tanto na interação entre alunos como na busca por maiores informações sobre o contexto de sua comunidade escolar e social. Os sujeitos respondentes indicam que 0 uso dos livros favorece o desenvolvimento da iniciativa dos estudantes, pressupondo que os atuais modelos editoriais deste segmento trazem modelos de pesquisas individuais e coletivas. $O$ fragmento abaixo auxilia para notarmos essa direção. 
Sujeito 3 - Os alunos do 3 a série, depois de estudarem no livro um determinado assunto, pediram espontaneamente se podiam fazer um trabalho para ver a situação do seu bairro e depois analisar os dados, conforme o livro. As atividades do livro ajudaram para ligar a escola com a vida dos alunos, isso não é bom?.

Na procura por relacionar, comparar e analisar conteúdos estatísticos, os professores do Ensino Médio buscam nos livros didáticos conceitos e atividades que busquem aproximar os alunos de situações significativas, tomando como objetivo o desenvolvimento da criticidade em relação às informações que estão trabalhando. Essa questão também auxilia na reflexão acerca do papel central ainda exercido pelo livro didático na organização curricular da educação básica brasileira. O professor mobiliza um conjunto de esforços, de saberes e práticas, na direção de uma educação apropriada à sociedade do tempo e do espaço em que vive. Os próximos dois fragmentos explicitam essa perspectiva.

Sujeito 7 - Procuro atividades em mais de um livro didático para os meus alunos realizarem e também uso textos de jornais e revistas para lermos e analisarmos e o que está ali impresso pode ser validado ou se somente é um gráfico bonitinho que não serve para nada. Não basta só ter os conteúdos nas listas da escola, precisamos fazer com que eles sejam úteis.

Utilizando - se ainda das concepções de Choppin (2004), historicamente, o livro didático tem funções que se associam a fatores de ordem social, econômica, cultural, temporal, política, dentre outros. Uma das funções, denominada pelo autor como função referencial, trata o livro didático como uma cópia do programa curricular a ser seguido, e argumenta que "em todo o caso, ele constitui o suporte privilegiado dos conteúdos educativos, o depositário dos conhecimentos, técnicas ou habilidades que um grupo social acredita que seja necessário transmitir às novas gerações" (ibidem, p. 553).

Sujeito 1 - Utilizo o livro didático adotado pela escola. Nele encontro as definições e atividades que se referem aos conteúdos. Primeiro faço com os alunos estas atividades, só depois elaboro atividades que envolvem a planilha do Excel. Uso esses programas também, mas a base sempre são os planos de estudos da minha escola.

Nota-se nas respostas apresentadas que o livro didático ainda é considerado pelos professores como um recurso indispensável, difundido nas aulas de Estatística do Ensino Médio. Uma das razões para isso talvez seja o fato de que ele é acessível a praticamente todos os alunos das escolas brasileiras, ora distribuído em larga escala pelas políticas de Estado para as escolas públicas, ora nos pacotes de apostilamento do ensino produzidos por grandes grupos empresariais que atuam na Educação, movimento típico das escolas particulares do País. Ou seja, é uma ferramenta que tem fácil manuseio, seus conteúdos, em geral, e, especificamente, os de Estatística, são atualizados e trazem situações-problema que se aproximam do cotidiano social dos estudantes. Ao fazerem uso desses materiais, os docentes tendem a privilegiar somente alguns dos principais conceitos estatísticos. Enfim, a partir de uma tradição pedagógica já consolidada no Brasil, os professores do Ensino Médio, ao ensinarem Estatística, seguem atribuindo centralidade ao uso dos livros didáticos na composição pedagógica de suas aulas, ou seja, o manuseio de tais materiais apresenta-se como um dos saberes da ação pedagógica mapeados nesta investigação. 


\section{CONCLUSÃO}

Ao finalizar este texto sobre os saberes mobilizados pelos docentes ao ensinarem Estatística no Ensino Médio algumas considerações podem ser observadas. Primeiramente, ressalta-se a importância que a Estatística possui nos currículos nacionais do Ensino Médio e nas situações do cotidiano, as quais ocupam e estão inseridas em largo espaço praticamente em todas as ciências. Em segundo lugar, enaltece-se que os saberes docentes são constituídos por múltiplas dimensões e cada uma delas é fundamental nas práticas profissionais dos professores. Observando o contexto da pesquisa, neste momento é possível afirmar que são os saberes da ação pedagógica que estão presentes nos depoimentos dos docentes e fazem parte de suas práticas, as quais apresentam como pano de fundo pressupostos teóricos que orientam tais saberes. Dentre estes, observou-se uma predominância do uso do livro didático como uma das ferramentas para o ensino da Estatística no Ensino Médio. E ainda percebe-se que cada docente apresenta especificidades no que tange as suas estratégias de ação; entretanto, importa destacar que seu foco está em relações de ensino e de aprendizagem que buscam relacionar conhecimentos estatísticos com o cotidiano, para que assim o aluno compreenda a importância que a Estatística possui no currículo escolar e, consequentemente em sua formação como cidadão.

\section{REFERÊNCIAS BIBLIOGRÁFICAS}

1. BATANERO, C. Los retos de la cultura estadística. In: JORNADAS INTERAMERICANAS DE ENSEÑANZA DE LA ESTADÍSTICA, 2002, Buenos Aires. Anais eletrônicos... Disponível em: < http://www.docentes.unal.edu.co/pnpachecod/docs/losretos.pdf >. Acesso em: 25 out. 2009.

2. BATANERO, C., Didática de la Estadística. Granada: Grupo de investigação em Educación Estadística do Departamento de Didática de la Matemática da Universidad de Granada, 2001.

3. BATANERO, C., GODINO, J., ESTEPA, A. Análisis Exploratório de datos: sus posibilidades en la enseñanza secundaria. Suma, n. 9, p. 25- 31, 1991.

4. BITTENCOURT, C. Livro didático e saber escolar (1810-1910). Belo Horizonte: Autêntica Editora, 2008.

5. BRASIL. Parâmetros Curriculares Nacionais: Matemática. Brasília: MEC/SEF, 1997.

6. BRASIL. Orientações Curriculares para $O$ Ensino Médio: Ciências da natureza e suas tecnologias. Brasília: MEC/SEB, v.2, 2006.

7. BRASIL. Ministério da Educação e Cultura. Guia de livros didáticos PNLD 2008: Matemática. Brasília: MEC, 2007.

8. CHOPPIN, A. História dos livros e das edições didáticas: sobre o estado da arte. Educação e Pesquisa, v.30, n.3, p. 549-566, set./dez. 2004.

9. DANTE, L. R. Livro didático de matemática: uso e abuso?. Em Aberto, Brasília, v.16, n.16, p. 83-90, jan/mar.1996.

10. FARIAS A., SOARES, J., CÉSAR, C. Introdução à estatística. Rio de Janeiro: Ed. LTC, 2003.

11. GAL, I. Adult's Statistical Literacy: Meanings, Components, Responsibilities - Appeares. 
Internacional Statistical Review, v.70, n.1, p. 1-33, 2002.

12. GAUTHIER, C. et al. Por uma teoria da pedagogia: pesquisas contemporâneas sobre os saberes docentes. ljuí: Ed. Unijuí, 2006.

13. LOPES, C. A. E. A probabilidade e a estatística no ensino fundamental: uma análise curricular. Campinas, 1998. Dissertação de mestrado - Faculdade de Educação - Universidade Estadual de Campinas , 1998.

14. LOPES, C. A. E. Literacia Estatística e INAF 2002. In: FONSECA, M. C. F. R. (Org.). Letramento no Brasil: Habilidades Matemáticas. São Paulo: Global, 2004. p. 187-200.

15. LOPES, C.A. E. O ensino da estatística e da probabilidade na educação básica e a formação dos professores. Caderno Cedes, Campinas, v. 28, n. 74, p. 57-73, abr. 2008.

16. MORAES, R., GALIAZZI. M. C. Análise textual discursiva. Ijuí: Ed. Unijuí, 2007.

17. PIMENTA, S. G. Formação de professores: identidade e saberes da docência. In: (Org.). Saberes pedagógicos e atividade docente. São Paulo: Cortez, 1999. p. 15-34.

18. SILVA, E. L., MENEZES, E. M. Metodologia da pesquisa e elaboração de dissertação. Florianópolis: UFSC, 2005.

19. WODEWOTZKI, M. L., L. JACOBINI, O. R. O Ensino de Estatística no contexto da Educação Matemática. In: BICUDO. M. A. V., BORBA, M. C. (Org.). Educação Matemática: pesquisa em movimento. São Paulo: Cortez, 2004. p. 232-249. 